\title{
Phase II study of motesanib in Japanese patients with advanced gastrointestinal stromal tumors with prior exposure to imatinib mesylate
}

\author{
Akira Sawaki · Yasuhide Yamada · Yoshito Komatsu • Tatsuo Kanda · Toshihiko Doi · \\ Masato Koseki · Hideo Baba $\cdot$ Yu-Nien Sun · Koji Murakami · Toshirou Nishida
}

Received: 24 May 2009 / Accepted: 29 July 2009 / Published online: 19 August 2009

(C) The Author(s) 2009. This article is published with open access at Springerlink.com

\begin{abstract}
Purpose Motesanib (AMG 706) is a multitargeted anticancer agent with an inhibitory action on the human vascular endothelial growth factor receptor, the platelet-derived growth factor receptor, and the cellular stem-cell factor receptor (KIT). The aim of this single-arm phase II clinical study was to assess the efficacy and safety of single-agent motesanib in Japanese patients with advanced gastrointestinal stromal tumors with prior exposure to imatinib mesylate.

Methods All patients had experienced progression or relapse while undergoing with imatinib as $400 \mathrm{mg} /$ day or higher. The patients were administered $125 \mathrm{mg}$ of motesanib once daily. The primary endpoint was overall response. Efficacy was evaluated according to the Response Evaluation Criteria in Solid Tumor, and safety was assessed
\end{abstract}

according to the Common Terminology Criteria for Adverse Events (version 3).

Results Of 35 enrolled and treated patients, no patient showed a complete response, and one patient showed a partial response (PR). Seven had stable disease (SD) for at least 24 months, two of whom continued to have SD for more than 2 years. The median progression-free survival time was 16.1 weeks. Motesanib was well tolerated; commonly reported treatment-related adverse events were hypertension, diarrhea, and fatigue. Anemia was the only hematological toxicity that was reported.

Conclusions One patient showed PR, and seven patients showed SD more than 24 weeks. Motesanib was found to be safe and well tolerated. The observed toxicities were consistent with Phase I study findings.

M. Koseki

Department of Surgery,

National Hospital Organization Kure Medical Center,

Hiroshima, Japan

H. Baba

Department of Surgical Pathology,

Kumamoto University Hospital, Kumamoto, Japan

Y.-N. Sun

Department of Pharmacokinetics and Drug Metabolism,

Amgen Inc., Thousand Oaks, CA, USA

K. Murakami

PET Center, Dokkyo University School of Medicine,

Tochigi, Japan

T. Nishida

Department of Digestive Surgery,

Osaka University Hospital, Osaka, Japan 
Keywords Motesanib - Angiogenesis inhibitor . Gastrointestinal stromal tumor (GIST)

\section{Introduction}

Gastrointestinal stromal tumor (GIST) is a rare stromal neoplasm that predominantly arises from the muscularis propria layers, representing the most common mesenchymal tumor of the gastrointestinal tract. Although the primary therapy for nonmetastatic GIST is surgical resection, there still remain unresectable cases of advanced or metastatic GIST. Unresectable GISTs are resistant to conventional chemotherapy and radiotherapy [1]. Before imatinib mesylate was introduced in clinical practice, the prognosis for patients with unresectable GIST was dismal, with a median survival period of 22 months [2].

The critical transforming and oncogenic mechanisms of GISTs are activating mutations in the stem-cell factor receptor, KIT tyrosine kinase [3]. About 5\% of GISTs are caused by activating mutations of the platelet-derived growth factor receptor alpha (PDGFRA), and are independent of $c$-kit mutations [4]. The $c$-kit and PDGFRA mutations appear to be alternative and mutually exclusive oncogenic mechanisms in GIST.

Imatinib mesylate blocks the constitutively activated form of KIT in GISTs, and has dramatically improved the outcome for patients with unresectable GIST [5]. Treatment with imatinib mesylate results in partial response (PR) or stable disease (SD) in approximately $80 \%$ of patients with advanced or metastatic GIST [6], and the 2-year survival rate of these patients is reported to be $70 \%$ [7].

However, approximately $10-15 \%$ of advanced GIST patients will suffer a progressive disease (PD) despite treatment with imatinib mesylate. Many of the patients who initially responded to imatinib mesylate therapy experience tumor progression after an average of 2 years of treatment [7, 8].

Sunitinib is an orally administered receptor tyrosine kinase (RET) inhibitor that targets multiple kinases and is used as a second-line treatment for patients with imatinibresistant or -intolerant GIST. A Phase III double-blind, placebo-controlled trial comparing sunitinib with placebo showed that the time to progression was significantly longer in the sunitinib group than in the placebo group (6.3 versus 1.5 months). Adverse reactions, though observed, were acceptable [9]. However, despite initial response or stabilization, the disease developed resistance in most patients after approximately 7 months. Because no therapies are available for patients with GIST once imatinib and sunitinib fail, there exists a need for alternative agents that block the signaling pathways in GIST cells.

Motesanib is a novel, synthetic, small molecule that strongly and selectively inhibits vascular endothelial growth factor receptors 1,2 , and 3, as well as the cellular KIT, the platelet-derived growth factor receptor (PDGFR), and the glial-derived nerve growth factor family ligand RET. The safety and pharmacokinetic (PK) profile of motesanib were evaluated in a Phase I, monotherapy, openlabel, dose-finding study [10]. In this study, motesanib showed clinical activity in patients with advanced refractory solid tumors; SD was observed in a significant proportion of the patients, although the overall tumor response rate was low.

The above findings prompted us to conduct a Phase II study to evaluate the efficacy, safety, and PK of motesanib in Japanese patients with advanced GIST, after failure or withdrawal of imatinib mesylate due to resistance or intolerance.

\section{Materials and methods}

\section{Patients}

Japanese patients with pathologically confirmed advanced or metastatic GIST were eligible for this study if they met the following criteria; age $\geq 20$ years; a proven KIT positive or activating mutation of PDGFR; prior imatinib mesylate therapy of $400 \mathrm{mg} /$ day or more for at least 8 weeks; disease progression or relapse while on previous treatment with imatinib mesylate; at least one tumor lesion measurable by a computed tomographic (CT) scan or magnetic resonance imaging (MRI); an Eastern Cooperative Oncology Group (ECOG) performance status (PS) of 0 to 2; a life expectancy of more than 3 months; adequate organ functions as defined by: neutrophils $\geq 1.5 \times 10^{3}$ cells $/ \mathrm{mm}^{3}$, platelets $\geq 1.0 \times 10^{4}$ cells $/ \mathrm{mm}^{3}$, hemoglobin $\geq 9.0 \mathrm{~g} / \mathrm{dl}$, serum creatinine $\leq 2.0 \times$ upper limit of normal (ULN), urine protein quantitative value of $\leq 1+$ on dipstick or $30 \mathrm{mg} / \mathrm{dl}$ in urinalysis, aspartate aminotransferase $\leq 2.5 \times$ ULN $(5.0 \times$ ULN in patients with liver metastasis), alanine aminotransferase $\leq 2.5 \times \mathrm{ULN}(5.0 \times \mathrm{ULN}$ in patients with liver metastasis), alkaline phosphatase $\leq 2.5 \times$ ULN $(5.0 \times$ ULN in patients with bone or liver metastasis), and total bilirubin $\leq 2.0 \times$ ULN. This protocol was approved by the Institutional Review Board at each study site. All patients provided written informed consent.

\section{Study design}

This study was an open-label and multicenter Phase II clinical study. The primary endpoint was the objective response rate to a once daily oral treatment with $125 \mathrm{mg}$ motesanib in patients with advanced GISTs who experienced disease progression or relapse while on imatinib mesylate treatment. (Sunitinib was not approved for imatinib-resistant 
GIST until 2 years after their study was completed.) The secondary endpoints were duration of response, progression-free survival (PFS), time to response, overall survival, and PK profiles of motesanib in Japanese patients with advanced GISTs.

The dose was firstly reduced to $100 \mathrm{mg}$, and if need be, to $75 \mathrm{mg}$ in the second time. If the grade 3 adverse event (AE) is not adequately controlled with appropriate supportive care or a grade $4 \mathrm{AE}$ occurs, motesanib was withheld. Once the grade 3 or $4 \mathrm{AE}$ has resolved to baseline or grade $\leq 1$ for nonhematologic toxicities or baseline or grade $\leq 2$ for hematologic toxicities, the dose was reduced by $25 \mathrm{mg}$ and treatment was resumed. If treatment with motesanib was withheld for $>21$ days, the patient should be withdrawn from the treatment period and complete the end of study procedures. If a patient was receiving $75 \mathrm{mg}$ and requires a dose reduction, treatment with motesanib was stopped and the patient should complete the end of study procedures.

Tumor evaluation was performed after 8 weeks and at every 8 weeks thereafter, by using the modified Response Evaluation Criteria in Solid Tumor (RECIST). A confirmation of tumor response was performed by using the modified RECIST at least 4 weeks after a complete response (CR) or PR was first documented. An appointed radiographic image reviewer who was independent of the study site or the study sponsor reviewed CT or MRI of all patients.

The severity of AEs was graded according to Common Toxicity Criteria for Adverse Events (CTCAE, version 3). Special attention was paid to cardiac function, hypertension, hypothyroidism, and cholecystitis. Laboratory assessments (serum chemistry, hematology, thyroid hormones, blood pressure, and electrocardiogram) were performed every 2 weeks.

Ten patients had the following PK parameters: maximum observed plasma concentration $\left(C_{\max }\right)$, terminal elimination half-life $\left(t_{1 / 2}\right)$, area under the plasma concentrationtime curve from time 0 to $24 \mathrm{~h}$ after dosing $\left(\mathrm{AUC}_{0-24}\right)$, concentration at $24 \mathrm{~h}$ after dosing $\left(C_{24}\right)$, maximum plasma concentration time $\left(t_{\max }\right)$, the area under the plasma concentration versus time curve from 0 to infinity ( $\mathrm{AUC}_{0 \text {-inf }}$ ), and apparent plasma clearance $(\mathrm{CL} / \mathrm{F})$. These $\mathrm{PK}$ parameters of motesanib were calculated by the standard noncompartmental model using WinNonlin software version 4.1e (Pharsight Corporation, Mountain View, CA, USA) and summarized according to the study day and history of gastrectomy using descriptive statistics. Individual plasma concentration-time profiles were summarized by history of gastrectomy.

\section{Statistical analysis}

Descriptive statistics are provided for each endpoint. The safety analysis population consisted of all patients who received at least one dose of motesanib. The objective response rate and its two-sided $95 \%$ confidence interval ( $95 \%$ CI) were calculated. The CI was constructed by the exact method described by Collett [10]. For a PFS, calculated as the number of days between the first dose of motesanib and the date when radiological evidence of disease progression is determined (date of CT scan/MRI), or death (regardless of cause), whichever comes first (date of PD or death minus date of first dose of motesanib), KaplanMeier curve (with two-sided 95\% CI) was generated and its standard error was calculated using Greenwood's formula. Statistical analyses were performed using the SAS statistical software package (SAS Institute Inc., Cary, NC, USA) [11].

\section{Results}

Patient population

A total of 35 patients were enrolled and treated with motesanib between November 2005 and June 2006 at the following sites: Aichi Cancer Center Hospital, Osaka University Hospital, National Cancer Center Hospital, Hokkaido University Hospital, Niigata University Hospital, National Cancer Center Hospital East, National Hospital Organization Kure Medical Center, and Kumamoto University Hospital. One patient did not undergo baseline CT assessment. Hence, 34 patients were eligible for tumor response evaluation, and 35 for toxicity evaluation. Baseline demographic and clinical characteristics are summarized in Table 1. Of the 35 patients enrolled, 17 (49\%) were female and the median age was 62.0 years (range 3183 years). Every patient was diagnosed as having GIST with positive immunoreactivity for KIT protein. The most common primary sites of the tumor were the small intestine $(n=17)$ and the stomach $(n=10)$. The other sites of the tumor were the colon $(n=2)$ and the rectum $(n=2)$. All patients had received treatment with imatinib mesylate but not with other tyrosine kinase inhibitors. The mean time from the last imatinib treatment was 0.9 months (range 0.2-5.5 months).

\section{Outcome measures}

The tumor response as assessed by an independent radiographic image reviewer is shown in Table 2 . No CR was observed among the 35 patients enrolled in this study. One patient (3\%; 95\% CI $0.1-14.9 \%)$ had a PR and seven patients $(20 \%)$ demonstrated SD for at least 24 months, two of whom continued to have SD for more than 2 years. Twelve additional patients had SD lasting for 12 weeks or more. Thirteen patients experienced disease progression within 12 weeks. The patient with PR had a gastric GIST 
Table 1 Baseline characteristics

\begin{tabular}{ll}
\hline & All patients $(N=35)$ \\
\hline Sex, $n(\%)$ & \\
Female & $17(49)$ \\
Male & $18(51)$ \\
Age & \\
Median & 62.0 \\
Min, max & 31,83 \\
Age group, $n(\%)$ & \\
$<65$ years & $23(66)$ \\
$\geq 65$ years & $12(34)$ \\
$\geq 75$ years & $4(11)$ \\
ECOG PS, $n(\%)$ & \\
0 & $24(69)$ \\
1 & $9(26)$ \\
2 & $2(6)$ \\
Site of primary tumor at diagnosis, $n(\%)$ & \\
Small intestine & $17(49)$ \\
Stomach & $10(29)$ \\
Colon & $2(6)$ \\
Rectum & $2(6)$ \\
\hline
\end{tabular}

Table 2 Best tumor response per modified RECIST per independent review

\begin{tabular}{ll}
\hline & $\begin{array}{l}\text { All patients } \\
(N=35)\end{array}$ \\
\hline $\begin{array}{l}\text { Patients with measurable disease at baseline } \\
\text { Response assessment, } n(\%)\end{array}$ & $34(97)$ \\
Confirmed CR & $0(0)$ \\
Confirmed PR & $1(3)$ \\
SD $^{\text {a }}$ & $19(54)$ \\
PD & $13(37)$ \\
Unevaluable & $1(3)$ \\
Not done & $1(3)$ \\
Confirmed objective response (CR or PR) & $1(3)$ \\
95\% CI & $0.1-14.9$ \\
Durable SD & $7(20)$ \\
\hline
\end{tabular}

Full analysis set includes all patients who received at least one dose of motesanib

${ }^{a}$ Patients with a response assessment of PR or CR that is not subsequently confirmed at least 4 weeks later are included as SD

${ }^{b}$ Unevaluable includes patients with a response assessment of CR, $\mathrm{PR}$, or SD prior to the scheduled first assessment of response without an additional assessment of response

c Binomial proportion with exact $95 \%$ CI

d Durable SD is defined as having a best response on study as SD with a duration of $\geq 24$ weeks from study day 1

with spindle-cell type, exon 11 mutation, liver, and peritoneal metastases, and had initially responded to imatinib with SD as assessed by RECIST (Fig. 1). The median PFS
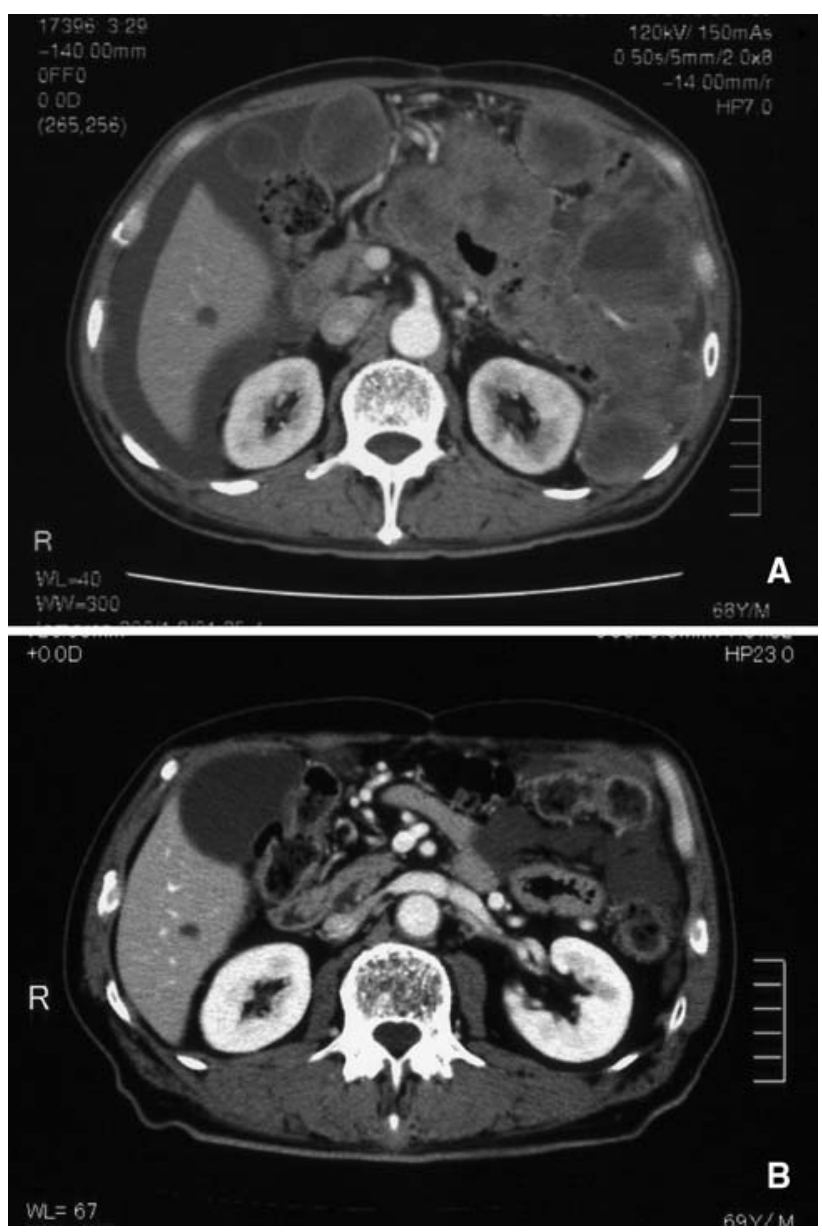

Fig. 1 A 68-year-old male with a primary GIST of the stomach and recurrent liver and peritoneal metastases. a Pre-treatment CT scan shows multiple low-density masses. b CT scan obtained after 3 months of treatment with once daily motesanib $125 \mathrm{mg}$ shows that the multiple lesions have become significantly smaller and less dense

time of motesanib was 16.1 weeks $\quad(95 \%$ CI 8.4 32.0 weeks; Fig. 2).

Safety and tolerability

Table 3 summarizes treatment-related adverse events (TRAEs) (patient incidence $\geq 15 \%$ ). The most frequent nonhematologic TRAEs included hypertension $(63 \%$ of patients), diarrhea (51\%), and fatigue (43\%). Five patients (14\%) experienced grade 3 hypertension and two patients (6\%) experienced grade 3 fatigue. The only hematological toxicity was anemia (grade 2 in $3 \%$ of patients, grade 3 in $6 \%$ of patients, and grade 4 in $0 \%$ of patients). One patient (3\%) experienced grade 4 hyperuricemia. No grade 5 TRAEs occurred.

Previous motesanib studies have reported an increased occurrence of cholecystitis in patients receiving motesanib, 
Fig. 2 Kaplan-Meier estimates of PFS

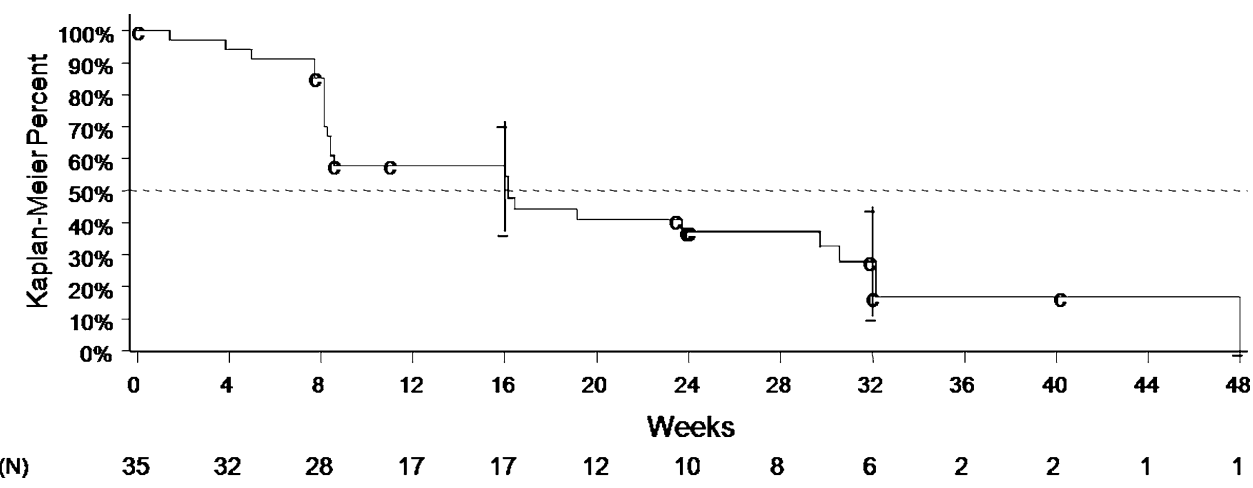

specifically at a dose of $75 \mathrm{mg}$ twice daily continuously. The etiology of cholecystitis observed in patients receiving motesanib is unknown. Cholecystitis was not reported in this study. Gallbladder disorder was reported in three patients, specifically extended gallbladder or wall thickening, which was incidentally discovered in these patients on ultrasound sonography (US). The patients had not undergone US before starting motesanib treatment, nor were these disorders detected on routine CT scanning.

Figure 3 and Table 4 summarize the results of the intensive PK analyses. After a single-dose oral administration of $125 \mathrm{mg}$ on day 1 , motesanib was rapidly absorbed, with an overall median $t_{\max }$ of $0.75 \mathrm{~h}$; a similar median $t_{\max }$ value $(0.79 \mathrm{~h})$ was observed after daily administration of motesanib on day 29. The mean $C_{\max }, \mathrm{AUC}_{0-24}$, and $C_{24}$ were slightly lower on day 29 than on day 1 , indicating that there was no accumulation after daily administration. The day 29 to day 1 mean ratios were $0.62,0.71$, and 0.80 for $C_{\max }, \mathrm{AUC}_{0-24}$, and $C_{24}$, respectively, for all evaluable patients.

Table 3 TRAE (15\% or more of the patients)

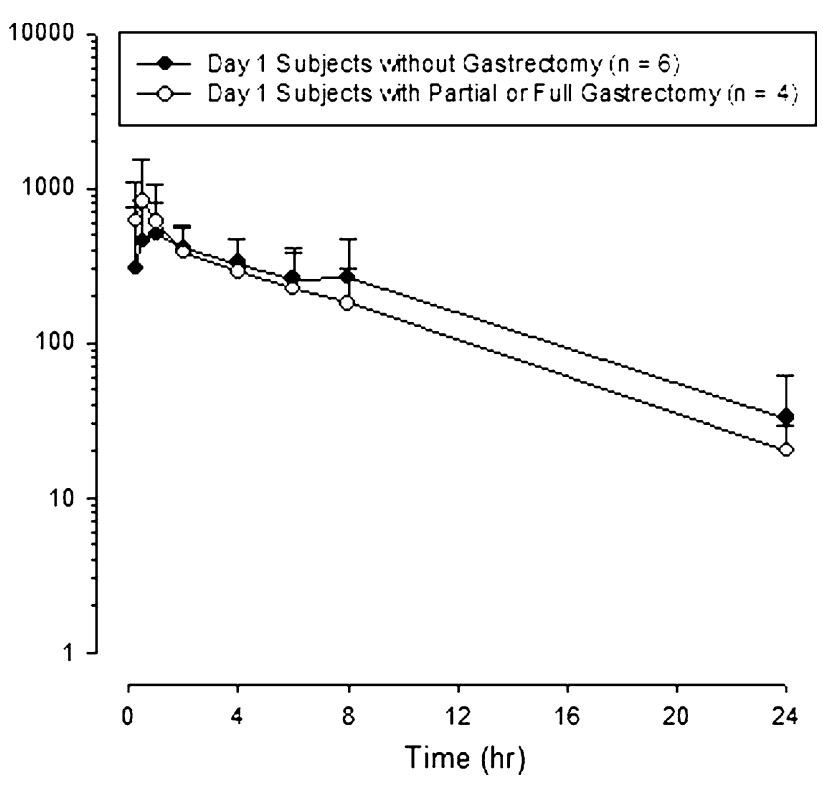

Fig. 3 Mean concentration-time profiles after oral administration of $125 \mathrm{mg}$ of motesanib on day 1 in patients without gastrectomy and in patients with partial or full gastrectomy

\begin{tabular}{lllll}
\hline Preferred term & \multicolumn{2}{l}{$\begin{array}{l}\text { Number of patients } \\
\text { reporting TRAE, } n(\%), 35(100)\end{array}$} & $\begin{array}{l}\text { All patients } \\
(N=35)\end{array}$ \\
\cline { 2 - 5 } & Grade $1 / 2$ & Grade 3 & Grade 4 & All grades \\
\hline Anemia & $1(3)$ & $2(6)$ & $0(0)$ & $3(9)$ \\
Hypertension & $17(48)$ & $5(14)$ & $0(0)$ & $22(63)$ \\
Diarrhea & $18(51)$ & $0(0)$ & $0(0)$ & $18(51)$ \\
Fatigue & $13(38)$ & $2(6)$ & $0(0)$ & $15(43)$ \\
Headache & $11(31)$ & $0(0)$ & $0(0)$ & $11(31)$ \\
Weight decreased & $11(31)$ & $0(0)$ & $0(0)$ & $11(31)$ \\
Rash & $10(29)$ & $0(0)$ & $0(0)$ & $10(29)$ \\
Anorexia & $5(14)$ & $4(11)$ & $0(0)$ & $9(26)$ \\
Nausea & $8(23)$ & $1(3)$ & $0(0)$ & $9(26)$ \\
Blood thyroid-stimulating & $8(23)$ & $0(0)$ & $0(0)$ & $8(23)$ \\
$\quad$ hormone increased & $8(23)$ & $0(0)$ & $0(0)$ & $8(23)$ \\
Dysphonia & $6(17)$ & $1(3)$ & $0(0)$ & $7(20)$ \\
Protein urine present & $6(17)$ & $0(0)$ & $0(0)$ & $6(17)$ \\
Dry skin & $5(15)$ & $1(3)$ & $0(0)$ & $6(17)$ \\
Vomiting & & & &
\end{tabular}


Table 4 Summary of PK parameters following oral administration of $125 \mathrm{mg}$ motesanib on days 1 and 29

\begin{tabular}{|c|c|c|c|c|}
\hline PK parameter & $N$ & $\begin{array}{l}\text { Day } 1 \\
\text { Mean } \pm \text { SD }\end{array}$ & $\begin{array}{l}\text { Day } 29 \\
\text { Mean } \pm \text { SD }\end{array}$ & $\begin{array}{l}\text { Day 29:Day } 1 \text { ratio } \\
\text { Mean } \pm \text { SD }\end{array}$ \\
\hline \multicolumn{5}{|l|}{ All evaluable patients } \\
\hline$t_{\max }(\mathrm{h})^{\mathrm{a}}$ & 10 & $0.75(0.25-2.0)$ & $0.79(0.50-4.0)$ & NA \\
\hline$C_{\max }(\mathrm{ng} / \mathrm{ml})$ & 10 & $800 \pm 439$ & $488 \pm 363$ & $0.62 \pm 0.20$ \\
\hline $\mathrm{AUC}_{0-24}(\mu \mathrm{g} \mathrm{h} / \mathrm{ml})$ & 9 & $3.87 \pm 2.28$ & $2.51 \pm 2.10$ & $0.71 \pm 0.32$ \\
\hline $\operatorname{AUC}_{0-\text { inf }}(\mu \mathrm{g} \mathrm{h} / \mathrm{ml})$ & 9 & $4.14 \pm 2.47$ & NA & NA \\
\hline$t_{1 / 2, z}(\mathrm{~h})$ & 8 & $5.42 \pm 1.51$ & $4.27 \pm 1.26$ & NA \\
\hline $\mathrm{CL} / \mathrm{F}(1 / \mathrm{h})$ & 9 & $41.1 \pm 22.3$ & $69.3 \pm 31.8$ & NA \\
\hline$C_{24}(\mathrm{ng} / \mathrm{ml})$ & 9 & $27.6 \pm 23.8$ & $12.9 \pm 15.4$ & $0.80^{\mathrm{b}} \pm 1.17$ \\
\hline \multicolumn{5}{|c|}{ Evaluable patients with no prior gastrectomy } \\
\hline$t_{\max }(\mathrm{h})^{\mathrm{a}}$ & 6 & $1.0(0.25-2.0)$ & $1.0(0.50-4.0)$ & NA \\
\hline$C_{\max }(\mathrm{ng} / \mathrm{ml})$ & 6 & $692 \pm 312$ & $354 \pm 193$ & $0.53 \pm 0.16$ \\
\hline $\mathrm{AUC}_{0-24}(\mu \mathrm{g} \mathrm{h} / \mathrm{ml})$ & 5 & $3.91 \pm 2.43$ & $1.93 \pm 0.67$ & $0.67 \pm 0.39$ \\
\hline $\operatorname{AUC}_{0-\text { inf }}(\mu \mathrm{g} \mathrm{h} / \mathrm{ml})$ & 5 & $4.27 \pm 2.73$ & NA & NA \\
\hline$t_{1 / 2, z}(\mathrm{~h})$ & 4 & $5.20 \pm 1.79$ & $4.32 \pm 1.89$ & NA \\
\hline $\mathrm{CL} / \mathrm{F}(1 / \mathrm{h})$ & 5 & $40.7 \pm 24.5$ & $71.5 \pm 26.0$ & NA \\
\hline$C_{24}(\mathrm{ng} / \mathrm{ml})$ & 5 & $33.5 \pm 31.1$ & $16.6 \pm 20.3$ & $1.11^{\mathrm{b}} \pm 1.57$ \\
\hline \multicolumn{5}{|c|}{ Evaluable patients with partial or full gastrectomy } \\
\hline$t_{\max }(\mathrm{h})^{\mathrm{a}}$ & 4 & $0.50(0.25-2.0)$ & $0.50(0.50-1.0)$ & NA \\
\hline$C_{\max }(\mathrm{ng} / \mathrm{ml})$ & 4 & $962 \pm 599$ & $689 \pm 492$ & $0.75 \pm 0.21$ \\
\hline $\mathrm{AUC}_{0-24}(\mu \mathrm{g} \mathrm{h} / \mathrm{ml})$ & 4 & $3.82 \pm 2.45$ & $3.23 \pm 3.16$ & $0.75 \pm 0.25$ \\
\hline $\operatorname{AUC}_{0-\text { inf }}(\mu \mathrm{g} \mathrm{h} / \mathrm{ml})$ & 4 & $3.99 \pm 2.49$ & NA & NA \\
\hline$t_{1 / 2, z}(\mathrm{~h})$ & 4 & $5.63 \pm 1.42$ & $4.22 \pm 0.38$ & NA \\
\hline $\mathrm{CL} / \mathrm{F}(1 / \mathrm{h})$ & 4 & $41.6 \pm 22.9$ & $66.4 \pm 42.2$ & NA \\
\hline$C_{24}(\mathrm{ng} / \mathrm{ml})$ & 4 & $20.2 \pm 9.2$ & $8.37 \pm 6.24$ & $0.40 \pm 0.16$ \\
\hline
\end{tabular}

Note: One patient did not have intensive sampling for day 29. This patient was excluded from the summary statistics

Parameters are presented to three significant figures when possible. Ratios are presented to two decimal places

Patients with elevated motesanib concentrations at $24 \mathrm{~h}$ post-dose were excluded from the $C_{24}, t_{1 / 2}$, AUC, and AUC-derived parameter summary statistics calculations, hence the reduced sample size for these parameters

$t_{\max }=$ the time the maximal plasma concentration was observed; $C_{\max }=$ the maximal observed plasma concentration after dosing; $\mathrm{AUC}_{0-24}=$ the area under the plasma concentration-time curve from time 0 to $24 \mathrm{~h}$ post-dose; $\mathrm{AUC}_{0 \text {-inf }}=$ the area under the plasma concentration-time curve from time 0 to infinite time; $t_{1 / 2, z}=$ estimated terminal-phase half-life; $\mathrm{CL} / \mathrm{F}=$ apparent clearance $\left(\mathrm{AUC}_{0-24}\right.$ was used to estimate $\mathrm{CL} / \mathrm{F}$ on day 29$)$; $C_{24}=$ the observed plasma concentration at $24 \mathrm{~h}$ after dosing; $N A$ not applicable

${ }^{a} t_{\max }$ is reported as a median (range) value, and is presented to two significant figures

${ }^{\text {b }}$ One patient had a $C_{24}$ ratio of 3.84 . The $C_{24}$ ratio (mean $\pm \mathrm{SD}$ ) excluding this patient is $0.42 \pm 0.30$ for all patients and $0.43 \pm 0.42$ for patients without gastrectomy

For the patients who had partial or full gastrectomy $(n=4)$, day $1 C_{\max }$ values were slightly higher $(<2$-fold $)$ and AUC values were similar to those who had no gastrectomy. Means for $C_{\max }$ and AUC values on day 29 were higher compared with those who had no gastrectomy but not significant. Median $t_{\max }$ values occurred earlier in patients with gastrectomy on both days 1 and 29 (median $t_{\max }=0.50 \mathrm{~h}$ with gastrectomy versus $1.0 \mathrm{~h}$ with no gastrectomy). $C_{24}$ values on days 1 and 29 were lower in patients with gastrectomy compared with those who had no gastrectomy, though the mean $t_{1 / 2}$ values were similar (mean $t_{1 / 2, z}$ value $=4.22$ versus $4.32 \mathrm{~h}$, respectively).

\section{Discussion}

Although regression of thyroid cancer, renal cell carcinoma, and leiomyosarcoma was observed in the Phase I study of motesanib [12], objective tumor regression was observed in only one patient (3\%) with GIST in this study. Motesanib administered as a single-agent was well tolerated, and a number of patients experienced prolonged stabilization of the disease. Seven $(20 \%)$ did not exhibit disease progression for a minimum of 24 weeks, and the median PFS was 16.1 weeks. Serious hematological AEs (grade 3/4) were observed after sunitinib treatment in the Phase III trial. The incidence of grade 
$3 / 4$ anemia, leukocytopenia, and neutrocytopenia was 4,4 , and $10 \%$, respectively [9]. Anemia, leukocytopenia, and neutropenia were also reported as AEs for patients treated with imatinib; the incidence of grade 3/4 anemia, leukocytopenia, and neutropenia in a large Phase III study was $2.0,1.4$, and $4.8 \%$, respectively [6]. The only hematological toxicity of motesanib was anemia (grade 2, 3\%; grade 3,6\%). Despite long-term exposure to motesanib, hematological toxicities were mild. Motesanib may therefore present an alternative treatment option for patients who experienced neutrocytopenia or thrombocytopenia after treatment with imatinib or sunitinib.

To evaluate the potential effect of gastrectomy on motesanib disposition, the motesanib PK profiles from patients with a history of gastrectomy were compared with those who did not have prior gastrectomy. Median $t_{\max }$ values occurred earlier in patients with gastrectomy on both days 1 and 29, suggesting faster absorption in patients with a history of gastrectomy. Since gastrectomy impacts the gastric emptying rate and the absorption rate resulting in increase in $C_{\max }$, these findings should be considered in the following clinical trials.

The current treatment options for patients with GIST after treatment failure with imatinib and sunitinib are limited to best supportive care and investigative therapies. This study shows that in Japanese patients with advanced GIST motesanib is well tolerated, and, although an objective tumor response was observed in only one patient, motesanib may have an impact on survival in a retrospective analysis. However, focusing on other clinically meaningful measures, such as the Choi criteria [13] that incorporating tumor density and small changes in tumor size as revealed by CT scanning, is more important than focusing on the tumor response rate, which may fail to identify a potentially effective therapy [14, 15]. Randomized, well-controlled studies with time to progression or survival as the primary endpoints of efficacy will be needed to identify agents for which a tumor regression effect is not anticipated. Results from such studies will help in making an informed decision of whether or not to continue the clinical development of such agents in GIST.

Acknowledgment This study was funded by Takeda Bio Development Center.

Open Access This article is distributed under the terms of the Creative Commons Attribution Noncommercial License which permits any noncommercial use, distribution, and reproduction in any medium, provided the original author(s) and source are credited.

\section{References}

1. DeMatteo RP, Heinrich MC, El-Rifai WM, Demetri GD (2002) Clinical management of gastrointestinal stromal tumors: before and after STI-571. Hum Pathol 33:466-477

2. DeMatteo RP, Lewis JJ, Leung D, Mudan SS, Woodruff JM, Brennan MF (2000) Two hundred gastrointestinal stromal tumors: recurrence patterns and prognostic factors for survival. Ann Surg 31:51-58

3. Hirota S, Isozaki K, Moriyama Y et al (1998) Gain-of-function mutations of c-kit in human gastrointestinal stromal tumors. Science 279:577-580

4. Heinrich MC, Corless CL, Duensing A et al (2003) PDGFRA activating mutations in gastrointestinal stromal tumors. Science 299:708-710

5. Joensuu H, Roberts PJ, Sarlomo-Rikala M et al (2001) Effect of the tyrosine kinase inhibitor STI571 in a patient with a metastatic gastrointestinal stromal tumor. N Engl J Med 344:1052-1056

6. Demetri GD, von Mehren M, Blanke CD et al (2002) Efficacy and safety of imatinib mesylate in advanced gastrointestinal stromal tumors. N Engl J Med 347:472-480

7. Verweij J, Casali PG, Zalcberg J et al (2004) Progression-free survival in gastrointestinal stromal tumours with high-dose imatinib: randomised trial. Lancet 364:1127-1134

8. Van Glabbeke M, Verweij J, Casali PG et al (2005) Initial and late resistance to imatinib in advanced gastrointestinal stromal tumors are predicted by different prognostic factors: a European Organisation for Research and Treatment of Cancer-Italian Sarcoma Group-Australasian Gastrointestinal Trials Group study. J Clin Oncol 23:5795-5804

9. Demetri GD, van Oosterom AT, Garrett CR et al (2006) Efficacy and safety of sunitinib in patients with advanced gastrointestinal stromal tumour after failure of imatinib: a randomised controlled trial. Lancet 368:1329-1338

10. Collett D (1991) Modelling binary data. Chapman \& Hall/CRC, London

11. SAS Institute Inc. (1999) SAS/STAT user's guide, version 8. Cary, NC

12. Rosen LS, Kurzrock R, Mulay M et al (2007) Safety, pharmacokinetics, and efficacy of AMG 706, an oral multikinase inhibitor, in patients with advanced solid tumors. J Clin Oncol 25:2369-2376

13. Choi H, Charnsangavej C, Faria SC et al (2004) CT evaluation of the response of gastrointestinal stromal tumors after imatinib mesylate treatment: a quantitative analysis correlated with FDG PET findings. Am J Roentgenol 183:1619-1628

14. Choi H, Charnsangavej C, Faria SC et al (2007) Correlation of computed tomography and positron emission tomography in patients with metastatic gastrointestinal stromal tumor treated at a single institution with imatinib mesylate: proposal of new computed tomography response criteria. J Clin Oncol 25:1753-1759

15. Benjamin RS, Choi H, Macapinlac HA et al (2007) We should desist using RECIST, at least in GIST. J Clin Oncol 25:1760-1764 